\title{
Luaran Transfer Embrio Simpan Beku pada Pasien Endometriosis Pasca Operasi dan Non Endometriosis yang Menjalani IVF di Klinik Permata Hati RSUP Dr. Sardjito
}

\author{
Rina Fatmawati ${ }^{1}$, Shofwal Widad ${ }^{2}$, Agung Dewanto ${ }^{3}$ \\ 1,2,3 Departemen Obstetri Dan Ginekologi \\ Fakultas Kedokteran, Kesehatan Masyarakat, dan Keperawatan \\ Universitas Gadjah Mada \\ Korespondensi: rinafatmawati29@gmail.com
}

Submisi: rinafatmawati29@gmail.com

\begin{abstract}
Background: Endometriosis is a chronic condition that is influenced by the hormone estrogen which affects women of childbearing age, and is associated with pelvic pain and infertility. In Vitro Fertilization (IVF) is currently the most efficient assisted reproductive technology and its high success rate is often done for infertility therapy in women associated with endometriosis.

Objective: The aim of this study is to determine whether postoperative endometriosis affected pregnancy outcomes in patients underwent frozen embryo transfer in IVF / ICSI programs.

Method: This Research is done with a retrospective cohort design. The data was taken from medical records, research subjects who met the inclusion and exclusion criteria. The research data was collected, processed and analyzed using SPSS 23 . Univariate, bivariate and multivariate data analysis was carried out to determine the effect between variables.

Results and Discussion: There were 458 research subjects in this study. Endometriosis patients were 119 subjects (26\%). 57 subjects were categorized as minimum-mild endometriosis (47.9\%) and moderate-severe subjects as many as 62 subjects (52.1\%). The biochemical pregnancy rate (36.31\%) and clinical pregnancy $(29.4 \%)$ in patients with endometriosis was slightly higher than in non-endometriosis. But statistically it did not affect success rate of achieving biochemical ( $p=0.428 ; \mathrm{RR} 0.89 ; 95 \% \mathrm{Cl}: 0.71-1.24)$ and clinical pregnancy ( $p=0.535 ; \mathrm{RR} 0.883 ; 95 \% \mathrm{Cl}$ : 0.63- 1.22). The rate of miscarriage in postoperative endometriosis patients was higher than non-endometriosis patients ( $88.6 \%$ vs $80.7 \%$ ) but was not statistically significant ( $p=0.294$; RR 1.69; $95 \% \mathrm{Cl}: 0.61-4.67)$. Biochemical and clinical pregnancies were significantly affected by age, infertility, endometrial thickness, embryo age and embryo quality. The incidence of miscarriage was affected by the ovarian stimulation protocol.

Conclusion: Endometriosis post operative statistically has no effect on pregnancy outcomes in the IVF / ICSI cycle with frozen embryo transfer compared with another cause of infertility.
\end{abstract}

Keywords: Endometriosis; In Vitro Fertilization; Clinical pregnancy; biochemical pregnancy; miscarriage

\begin{abstract}
ABSTRAK
Latar Belakang: Endometriosis merupakan kondisi kronis yang dipengaruhi oleh hormon estrogen sehingga mempengaruhi wanita usia subur, dan berhubungan dengan nyeri panggul serta infertilitas. In Vitro Fertilization (IVF) saat ini merupakan teknologi reproduksi berbantu yang paling efisien dan tingkat keberhasilannya tinggi yang sering dilakukan untuk terapi infertilitas pada wanita yang berhubungan dengan endometriosis.

Tujuan: Tujuan dari penelitian ini adalah untuk mengetahui apakah endometriosis pasca operasi mempegaruhi luaran kehamilan pasien yang menjalani transfer embrio simpan beku pada program bayi tabung (IVF/ICSI).

Metode: Penelitian dengan desain kohort retrospektif. Data diambil dari rekam medis, subyek penelitian yang memenuhi kriteria inklusi dan eksklusi. Data penelitian dikumpulkan, diolah dan dianalisis dengan menggunakan SPSS 23. Dilakukan analisis data univariat, bivariat dan multivariat untuk mengetahui pengaruh antar variabel.

Hasil dan Pembahasan: Sampel pada penelitian ini berjumlah 458 subyek penelitian. Penderita endometriosis sebanyak 119 subyek (26\%). Kategori endometriosis minimal-ringan 57 subyek (47,9\%) dan sedang-berat sebanyak 62 subyek (52,1\%). Angka kehamilan biokimiawi (36,31\%) dan kehamilan klinis $(29,4 \%)$ pada penderita endometriosis sedikit lebih tinggi dibandingkan pada non endometriosis. Namun secara statistik tidak mempengaruhi keberhasilan mencapai kehamilan biokimiawi $(p=0,428$; $R R$ 0,89; Cl 95\%: 0,71-1,24) maupun kehamilan klinis ( $p=0,535 ; R R ~ 0,883 ; C l 95 \%: 0,63-1,22)$. Angka miscarriage pada penderita endometriosis pasca operasi lebih tinggi daripada penderita non endometriosis $(88,6 \% \mathrm{vs} 80,7 \%)$ namun tidak bermakna secara ststistik ( $p=0,294$; RR 1,69; Cl 95\%: 0,61-4,67). Kehamilan biokimiawi dan kehamilan klinis dipengaruhi secara signifikan oleh usia, infertilitas, ketebalan endometrium, usia embrio dan kualitas embrio. Kejadian miscarriage dipengaruhi oleh protokol stimulasi ovarium.

Kesimpulan: Endometriosis secara statistik tidak berpengaruh terhadap luaran kehamilan pada siklus IVF/ICSI dengan transfer embrio simpan beku.
\end{abstract}

Kata kunci: Endometriosis; In Vitro Fertilization; Kehamilan Klinis; kehamilan biokimiawi, miscarriage 


\section{PENDAHULUAN}

Endometriosis merupakan kondisi kronis yang dipengaruhi oleh hormon estrogen sehingga mempengaruhi wanita usia subur, dan berhubungan dengan nyeri panggul serta infertilitas. ${ }^{1}$

Meskipun telah banyak penelitian yang berusaha untuk menjelaskan implikasi endometriosis terhadap fertilitas, namun sampai saat ini masih belum jelas mekanisme yang mendasarinya. ${ }^{2}$ Adanya peningkatan prevalensi subfertilitas pada pasien endometriosis mengindikasikan bahwa endometriosis mempengaruhi proses reproduksi. Pada kasus endometriosis pelvis yang berat terjadi adhesi peritoneal yang berat yang menganggu transpot gamet dan embrio, tapi pada wanita dengan endometriosis yang ringan dan tanpa adanya adhesi peritoneal penyebab infertilitas masih kabur. Meskipun begitu pada beberapa penelitian menyatakan bahwa pada wanita dengan endometriosis ringan yang telah menjalani tindakan pengambilan implan endometriosis mengalami peningkatan angka kehamilan dan peningkatan kesuksesan proses IVF. ${ }^{3}$

Derajat endometriosis mempengaruhi luaran IVF pada pasien endometriosis yang sebelumnya telah menjalani operasi sebelum prosedur IVF, dan interval waktu antara operasi dan IVF juga mempengaruhi luaran. ${ }^{4}$ Wanita dengan endometriosis stadium I dan II yang menjalani IVF / ICSI memiliki waktu yang jauh lebih singkat dalam mencapai kehamilan dan angka kelahiran hidup yang lebih tinggi jika semua endometriosis yang terlihat benar-benar telah dihilangkan pada operasi saat diagnosis. ${ }^{5}$

Beberapa peneliti menemukan rendahnya tingkat fertilitas pasien endometriosis disebabkan oleh defek implantasi yang dipengaruhi oleh tiga hal yaitu: kerusakan oosit dan embrio, kerusakan endometrium dan kelainan interaksi antara endometrium dan embrio. ${ }^{6}$
Endometriosis dapat mengganggu kesuburan melaluibeberapajalur, termasukinflamasiperitoneum dan gangguan endokrin, yang mengganggu fungsi ovarium dan pada akhirnya menurunkan kualitas oosit. Pengangkatan fokus peritoneal superfisial pada endometriosis mild ringan telah terbukti sedikit meningkatkan kesuburan, sedangkan reseksi endometrioma dan lesi infiltrasi dalam memiliki efek tidak terdokumentasi pada kesuburan. ${ }^{2}$

In Vitro Fertilization (IVF) saat ini merupakan teknologi reproduksi berbantu yang paling efisien dan tingkat keberhasilannya tinggi yang sering dilakukan untuk terapi infertilitas pada wanita yang berhubungan dengan endometriosis. Meskipun sampai saat ini masih dipertanyakan apakah endometriosis sendiri mempunyai efek negatif terhadap keberhasilan IVF atau tidak. ${ }^{7}$ Suatu metaanalisis menyimpulkan bahwa endometriosis mengganggu terhadap seluruh aspek proses reproduksi, sehingga angka kesuksesan IVF pada penderita endometriosis lebih rendah daripada wanita dengan indikasi IVF lainnya. ${ }^{8}$

Kesuksesan IVF tidak hanya tergantung pada kualitas embrio tetapi juga pada reseptivitas endometrium. Endometrium pada siklus stimulasi ovarium belum benar-benar siap untuk implantasi embrio sehingga menurunkan reseptivitas endometrium, dilihat dari hasil evaluasi morfologi dan biomolekuler. ${ }^{9}$

Frozen Embrio Transfer (FET) saat ini memegang peranan penting dalam proses tekhnologi reproduksi berbantu, dengan membawa dua keuntunganya itu menurunkan angka kehamilan ganda karena jumlah embrio yang diimplantasikan dapat dikurangi, selain itu FET dapat memaksimalkan kemungkinan kehamilan dari setiap proses pengambilan oosit. ${ }^{10}$

Pada proses Frozen Embrio Transfer (FET) hiperstimulasi ovarium tidak terjadi, sehingga endometrium dapat dipersiapkan untuk implantasi embrio. ${ }^{11}$ Pada penderita endometriosis FET dapat 
memberikan keuntungan meningkatkan reseptivitas endometrium, mengingat reseptivitas endometrium pada wanita endometriosis memang sudah rendah. ${ }^{12}$

\section{METODE}

Penelitian ini menggunakan studi kohort retrospektif untuk mengetahui apakah endometriosis pasca operasi berpengaruh terhadap keberhasilan transfer embrio simpan beku pada program bayi tabung (IVF/ICSI).

Subyek penelitian adalah semua wanita yang menjalani transfer embrio simpan beku pada program bayi tabung (IVF/ICSI) dari tahun 2013 sampai dengan 2018 di klinik infertilitas Permata Hati RSUP dr. Sardjito. Yang telah diseleksi berdasarkan kriteria inklusi dan ekslusi.

Kriteria Inklusi meliputi: Wanita yang menjalani program IVF dengan transfer embrio simpan beku di Klinik Permata Hati RSUP Dr. Sardjito tahun 2013 hingga 2018 dengan disertai diagnosis endometriosis sebagai kelompok subyek sedangkan pasien yang menjalani program IVF dengan transfer embrio simpan beku dengan disertai diagnosis apapun selain endometriosis adalah kelompok kontrol. Penderita endometriosis stadium I, II, II, IV yang ditegakkan dengan laparoskopi maupun laparotomi dengan hasil patologi anatomi menyatakan sebagai endometriosis. Semua penderita infertilitas yang menjalani program IVF dengan transfer embrio simpan beku sebagai grup kontrol.

Kriteria ekslusi meliputi: adanya faktor predisposisi kegagalan implantasi seperti trombofilia, PCOS, malformasi uterus (didelfis, septa, bikornu dan hipoplasi uterus), Pasien dengan rekam medis yang tidak lengkap.

Beberapa parameter yang diambil pada penelitian ini meliputi faktor ibu identitas ibu, usia, pendidikan ibu, paritas, indeks massa tubuh, derajat endometriosis, ketebalan endometrium dan protokol stimulasi ovarium.
Faktor embrio yang dilihat meliputi jumlah embrio yang ditransfer, usia embrio saat di transfer, dan kualitas embrio

Luaran kehamilan meliputi kehamilan biokimiawi, kehamilan kimia dan kehamilan klinis.

Data yang sudah terkumpul kemudian diolah untuk mencari hubungan variabel yang dianalisis menggunakan SPSS 23 dengan uji Chisquare/Fisher dilanjutkan dengan regresi logistik.

\section{HASIL DAN PEMBAHASAN}

Sampel diambil dari data sekunder rekam medis RSUP Dr. Sardjito sejak 1 Januari 2013 sampai 31 Desember 2018. Didapatkan 491 rekam medik pasien yang menjalani transfer embrio simpan beku. Dari populasi sampel tersebut, subyek penelitian yang memenuhi kriteria inklusi dan eksklusi sebanyak 458 subyek penelitian.

Tabel 1 menunjukkan karakteristik subyek penelitian. Pasien menderita endometriosis sebanyak 119 orang (26\%). Terbagi menjadi endometriosis minimal-ringan sebanyak 57 orang $(47,9 \%)$, endometriosis sedang-berat 62 orang (52\%). Pada saat dilakukan FET usia dibawah 35 tahun sebanyak 230 orang $(50,2 \%)$ dan usia 35 Tahun keatas sebanyak 228 orang $(49,8 \%)$. Dengan rata rata usia adalah 34,73 tahun. Pendidikan subyek penelitian sebagian besar adalah pendidikan tinggi sebanyak 410 orang $(89,5 \%)$ dan sebagian besar adalah wanita bekerja sebanyak 327 orang $(71,4 \%)$. Status infertilitas pasien sebagian besar adalah infertil primer sebanyak 326 orang $(71,2 \%)$ sedangkan infertil sekunder sebanyak 132 orang $(28,8 \%)$. Sebagian besar subyek penelitian indek massa tubuhnya kurang dari 25 sebanyak 335 orang $(73,1)$.

Ketebalan endometrium sebagian besar lebih dari $8 \mathrm{~mm}$ sebanyak 353 orang $(77,1 \%)$, sebagian besar menggunakan protokol pendek sebanyak 401 orang (87,6\%). Jumlah embrio yang diimplantasikan seagian besar berjumlah 2 embrio sebanyak 323 (70,5\%) dengan usia embrio lebih banyak saat D3 265 (57,9\%). 
Tabel 1. Karakteristik Subyek Penelitian

\begin{tabular}{|c|c|c|}
\hline Variabel & Jumlah & (\%) \\
\hline \multicolumn{3}{|l|}{ Endometriosis } \\
\hline Tidak & 339 & 74.0 \\
\hline Ya & 119 & 26.0 \\
\hline \multicolumn{3}{|c|}{ Derajat Endometriosis } \\
\hline Minimal-ringan & 57 & 47.9 \\
\hline Sedang-berat & 62 & 52.1 \\
\hline \multicolumn{3}{|l|}{ Usia } \\
\hline$<35$ & 230 & 50.2 \\
\hline$\geq 35$ & 228 & 49.8 \\
\hline \multicolumn{3}{|l|}{ Pendidikan } \\
\hline Tinggi & 410 & 89.5 \\
\hline Dasar- Menengah & 48 & 10.5 \\
\hline \multicolumn{3}{|l|}{ Pekerjaan } \\
\hline Tidak bekerja & 131 & 28.6 \\
\hline Bekerja & 327 & 71.4 \\
\hline \multicolumn{3}{|l|}{ IMT } \\
\hline$<25$ & 335 & 73.1 \\
\hline$>25$ & 123 & 26.9 \\
\hline \multicolumn{3}{|l|}{ Infertilitas } \\
\hline Sekunder & 132 & 28.8 \\
\hline Primer & 326 & 71.2 \\
\hline \multicolumn{3}{|c|}{ Ketebalan Endometri-um } \\
\hline$\geq 8$ & 353 & 77.1 \\
\hline$<8$ & 105 & 22.9 \\
\hline \multicolumn{3}{|c|}{ Protokol stimulasi ovarium } \\
\hline Long protokol & 57 & 12.4 \\
\hline Short protokol & 401 & 87.6 \\
\hline \multicolumn{3}{|l|}{ Jumlah Embrio } \\
\hline 1 & 135 & 29.5 \\
\hline 2 & 323 & 70.5 \\
\hline \multicolumn{3}{|l|}{ Usia Embrio } \\
\hline D5 & 193 & 42.1 \\
\hline D3 & 265 & 57.9 \\
\hline \multicolumn{3}{|l|}{ Kualitas embrio } \\
\hline 1 & 90 & 19.7 \\
\hline 1 dan 1 & 106 & 23.1 \\
\hline 1 dan 2 & 124 & 27.1 \\
\hline 2 dan 2 & 96 & 21.0 \\
\hline 2 & 42 & 9.2 \\
\hline
\end{tabular}

Tabel 2 menunjukkan pasien berhasil hamil biokimiawi 152 (33,2\%), kehamilan klinis sebanyak 123 orang $(26,9 \%)$. Pasien mengalami miscarriage sebanyak 102 orang (22,3\%), pasien yang berhasil melanjutkan kehamilannya sebanyak 21 orang $(4,6 \%)$.

Tabel 2 . Luaran Kehamilan

No Luaran Kehamilan Jumlah

\section{(\%)}

1 Kehamilan Bio-kimiawi

$\begin{array}{lll}\text { Ya } & 152 & 33.2 \\ \text { Tidak } & 306 & 66.8\end{array}$

2 Kehamilan Klinis

$\begin{array}{lll}\text { Ya } & 123 & 26.9 \\ \text { Tidak } & 335 & 73.1\end{array}$

3 Misscarriage

\begin{tabular}{lcc} 
Hamil & 21 & 17,1 \\
Misscarriage & 102 & 82,9 \\
\hline
\end{tabular}

Pada tabel 3 hasil analisis bivariat endometriosis tidak berpengaruh terhadap pencapaian kehamilan biokimiawi dibandingkan dengan pasien non endometriosis. Pasien tidak endometriosis berhasil hamil biokimiawi sebanyak $32,2 \%$ sedangkan pasien endometriosis sedikit lebih banyak yaitu $36,1 \%$, tidak menunjukkan perbedaan yang bermakna $(p=0,428 ; R R=0,89 ; C l$ 95\%: 0,70-1,24). Derajat endometriosis tidak berpengaruh terhadap kehamilan biokimiawi. Namun subyek dengan derajat endometriosis minimal-ringan berhasil hamil lebih banyak yaitu $40,4 \%$ sedangkan derajat sedang-berat berhasil hamil biokimiawi sebanyak 32,3\% tidak menunjukkan perbedaan bermakna secara stastistik ( $p=0,359 ; R R=1,25: C l$ 95\% 0,772,02 ). 
Tabel 3. Perbandingan Proporsi Endometriosis dan Derajat Endometriosis dengan Kehamilan Biokimiawi

\begin{tabular}{|c|c|c|c|c|c|c|}
\hline \multirow{2}{*}{ No } & \multirow{2}{*}{ Variabel } & \multicolumn{2}{|c|}{ Kehamilan Biokimiawi } & \multirow{2}{*}{$\mathbf{R R}$} & \multirow{2}{*}{$\mathrm{Cl} 95 \%$} & \multirow{2}{*}{ p-value } \\
\hline & & Ya (\%) & Tidak (\%) & & & \\
\hline \multirow[t]{3}{*}{1} & Endometriosis & & & & & \\
\hline & Tidak & 32,2 & 67,8 & 0,890 & $0,70-1,24$ & 0,428 \\
\hline & Ya & 36,1 & 63,9 & 1 (referant) & & \\
\hline \multirow[t]{3}{*}{2} & Derajat Endome & & & & & \\
\hline & Minimal-ringan & 40,4 & 59,6 & 1,25 & $0,77-2,02$ & 0,359 \\
\hline & Sedang-berat & 32,3 & 67,7 & 1 & & \\
\hline
\end{tabular}

Tabel 4 menunjukkan bahwa endometriosis tidak berpengaruh terhadap keberhasilan kehamilan klinis. Pasien tidak endometriosis mengalami kehamilan klinis sebanyak $26 \%$ sedangkan pasien dengan endometriosis yang berhasil hamil sebanyak 29,4\% ( $p=0,535 ; R R=0,883 ; \mathrm{Cl} 95 \%: 0,63-1,22$ ).
Pasien dengan derajat endometriosis minimalringan berhasil hamil lebih banyak yaitu 31,1\% sedangkan sedang-berat endometriosis lebih rendah yaitu $24,2 \%$ namun derajat endometriosis tidak berpengaruh terhadap pencapaian kehamilan klinis $(p=1,69 ; R R=1,45 ; C l 95 \% 0,82-2,55)$.

Tabel 4. Perbandingan Proporsi Endometriosis dan Derajat Endometriosis dengan Kehamilan Klinis

\begin{tabular}{|c|c|c|c|c|c|c|}
\hline \multirow{2}{*}{ No } & \multirow{2}{*}{ Variabel } & \multicolumn{2}{|c|}{ Kehamilan Klinis } & \multirow{2}{*}{$\mathbf{R R}$} & \multirow{2}{*}{$\mathrm{Cl} 95 \%$} & \multirow{2}{*}{ p-value } \\
\hline & & $\mathrm{Ya}(\%)$ & Tidak (\%) & & & \\
\hline \multirow[t]{3}{*}{1} & Endometriosis & & & & & \\
\hline & Tidak & 26,0 & 74,0 & 0,883 & $0,63-1,22$ & 0,535 \\
\hline & Ya & 29,4 & 70,6 & 1 & & \\
\hline \multirow[t]{3}{*}{2} & Derajat Endometriosis & & & & & \\
\hline & Minimal-ringan & 35,1 & 64,9 & 1,450 & $0,82-2,55$ & 1.698 \\
\hline & Sedang-berat & 24,2 & 75,8 & 1 & & \\
\hline
\end{tabular}

Tabel 5 menunjukkan pasien tidakendometriosis berhasil melanjutkan kehamilan lebih banyak $(19,3 \%)$ daripada pasien endometriosis. Kejadian misscarriage lebih besar pada pasien endometriosis
$(88,6 \%)$ dibandingkan pasien non endometriosis $(80,7)$ Namun tidak secara statistik tidak bermakna signifikan ( $R R=1,69 ; \mathrm{Cl} 95 \%$ 0,61-4,67; $P=0,294)$.

Tabel 5. Perbandingan Proporsi Endometriosis dan Derajat Endometriosis dengan Miscarriage

\begin{tabular}{|c|c|c|c|c|c|c|}
\hline \multirow{2}{*}{ No } & \multirow{2}{*}{ Variabel } & \multicolumn{2}{|c|}{ Miscarriage } & \multirow{2}{*}{$\mathbf{R R}$} & \multirow{2}{*}{$\mathrm{Cl} 95 \%$} & \multirow{2}{*}{ p-value } \\
\hline & & Hamil (\%) & Miscarriage (\%) & & & \\
\hline \multirow[t]{3}{*}{1} & Endometriosis & & & & & \\
\hline & Tidak & 19,3 & 80,7 & 1,69 & $0,6-4,67$ & 0,294 \\
\hline & Ya & 11,4 & 88,6 & 1 & & \\
\hline \multirow[t]{3}{*}{2} & Derajat Endome & & & & & \\
\hline & Minimal-ringan & 10,0 & 90,0 & 0,75 & $0,1-4,73$ & 1,000 \\
\hline & Sedang-berat & 13,3 & 86,7 & 1 & & \\
\hline
\end{tabular}


Hasil analisis bivariat menunjukkan bahwa kehamilan biokimiawi dengan variabel luar, usia ibu, status infertilitas, ketebalan endometrium, usia embrio dan kualitas embrio mempengaruhi kehamilan biokimiawi.

Keberhasilan tercapainya suatu kehamilan bergantung pada faktor-faktor pre dan post implantasi dan keberhasilan interaksi antara embrio dan endometrium maternal. Endometriosis berkaitan dengan infertilitas, dan diperkirakan 50\% wanita dengan endometriosis mengalami kesulitan dalam mencapai kehamilan secara alami. Menurut beberapa pakar hal ini sangat mungkin disebabkan karena tidak adekuatnya ekspresi biokimiawi pada saat implantasi. ${ }^{9}$

Hasil penelitian ini menunjukkan bahwa secara karakteristik subyek penelitian untuk usia hampir sebanding antara usia kurang dari 35 tahun dan lebih dari 35 tahun. Sebaran usia antara penderita endometriosis dan non endometriosis juga terdistribusi normal dengan $p=0,031(p>0,05)$. Sebagian besar subjek merupakan infertil primer. Tingkat pendidikan sebagian besar adalah pendidikan tinggi dan sebagian besar subjek adalah wanita bekerja. Hal ini dapat dipahami bahwa kesadaran untuk menangani infertilitas sampai dengan penanganan IVF lebih tinggi sejalan dengan tingginya tingkat pendidikan dan status ekonomi pasien dilihat dari status pekerjaan pasien.

Sebagian besar subyek tidak menderita endometriosis yaitu 339 orang (74\%) dan menderita endometriosis sebanyak 119 orang (26,01\%). Kemudian pasien endometriosis di kategorikan kembali menjadi kategori endometriosis minimalringan sebanyak 57 subyek $(47,9 \%)$ dan sedangberat yang sebanyak 62 subyek (52,1\%). Kasus endometriosis pada saat FET berjumlah $1 / 3$ dari jumlah sampel yang ada, karena infertilitas bukan hanya disebabkan oleh endometriosis, namum masih ada faktor yang lain, seperti kualitas sperma, penyakit ginekologi, dan lain sebagainya.

Kehamilan dibagi menjadi kehamilan biokimiawi, kehamilan klinis dan miscarriage. Kehamilan biokimiawi dari semua sampel berjumlah 152 orang $(33,2 \%)$, sedangkan pasien endometriosis yang berhasil hamil biokimiawi sedikit lebih tinggi yaitu sebanyak 43 orang $(36,1 \%)$. Penderita endometriosis minimal-ringan berhasil hamil sebanyak 22 orang $(40,4 \%)$ dan pada sedang-berat endometriosis sebanyak 20 orang (32,3\%).

Hasil ini tidak sejalan dengan penelitian sebelumnya yang banyak mengemukakan bahwa endometriosis mengurangi tingkat keberhasilan mencapai kehamilan. Namun dari derajat endometriosis menunjukkan bahwa keberhasilan implantasi pada pasien severe endometriosis keberhasilan implantasinya lebih rendah daripada mild endometriosis.

Hasil analisis bivariat antara endometriosis dengan kehamilan biokimiawi tidak didapatkan hubungan yang bermakna secara stastistik dengan $p=0,890(P>0,05)$. Demikian halnya dengan derajat endometriosis tidak didapatkan hubungan yang bermakna dengan kehamilan biokimiawi $p=0,359$ $(p>0,05)$.

Kehamilan klinis sebanyak 123 orang (26,9\%) dengan penderita endometriosis yang berhasil hamil klinis sebanyak 35 orang $(29,4 \%)$. Penderita endometriosis minimal-ringan yang berhasil hamil klinis sebanyak 20 orang $(35,1 \%)$ dan endometriosis sedang-berat sebanyak 15 orang $(24,2 \%)$.

Dari analisis bivariat antara endometriosis dengan kehamilan klinis tidak didapatkan hubungan yang bermakna dengan $p=0,535(p>0,05)$. Demikian pula dengan derajat endometriosis tidak memiliki hubungan yang bermakna terhadap kehamilan klinis $P=1,698(p>0,05)$.

Penelitian ini menunjukkan bahwa endometriosis tidak mempengaruhi terjadinya kehamilan biokimiawi dan kehamilan klinis, hal ini tidak sesuai dengan penelitian-penelitian sebelumnya yang menyatakan bahwa penderita endometriosis memiliki angka kehamilan yang lebih rendah dibandingkan dengan penyebab infertilitas yang lainnya. Kemungkinannya karena penderita endometriosis pada subyek penelitian ini telah dilakukan terapi dan tindakan sehingga meningkatkan angka keberhasilan dari kehamilan biokimiawi maupun kehamilan klinis.

Dalam suatu studi kohort menunjukkan pasien endometriosis yang menjalani IVF mengalami penurunan angka kehamilan terutama disebabkan oleh berkurangnya jumlah oosit dan laju pembuahan, 
terlepas dari tingkat keparahan penyakitnya. Manipulasi injeksi sperma intrasitoplasma yang tepat dapat meningkatkan hasil IVF. Kelompok endometriosis memiliki jumlah oosit yang diambil lebih rendah, tingkat pembuahan, tingkat implantasi, dan tingkat kehamilan klinis lebih rendah (masing-masing 7,6 $\pm 5,1,63,6 \%, 27,7 \%$, dan 45,2\%) dibandingkan dengan kelompok non-endometriosis (masing-masing $n=4267 ; 11,8 \pm 7,3,68,4 \%, 36,2 \%$, dan $55,2 \%$, ). Tidak ada perbedaan yang signifikan pada tingkat pembuahan, tingkat implantasi, dan tingkat kehamilan klinis antara pasien endometriosis ringan dan berat. $^{8}$

Hasil yang hampir sama dengan penelitian ini pada penelitian oleh Queiros et. al,2017 dengan studi kohort retrospektif pada 181 wanita usia 18-40 tahun dengan deep endometriosis dengan hasil tidak ada perbedaan yang signifikan secara statistik pada tingkat kehamilan bila dibandingkan pasien dengan deep endometriosis dengan kelompok nonendometriosis. Namun, ketika kita membandingkan angka keguguran, pasien non-endometriosis secara statistik signifikan bila dibandingkan dengan deep endometriosis. ${ }^{12}$

Penelitian oleh Ahmed et al, 2010 mengemukakan hal yang berbeda dengan populasi IVF umum, pada wanita dengan endometriosis yang menjalani IVF, pada persiapan endometrium untuk ET beku dengan agonis GnRH dibandingkan dengan siklus segar terkait dengan LBR yang lebih tinggi (16,9\% berbanding $11,9 \%)$ dan CPR yang jauh lebih tinggi $(18,2 \%$ berbanding $12,7 \%, P=0,048)$. Hasil ini menunjukkan bahwa, dalam kasus endometriosis, efek gabungan dari GnRHa pada endometrium dan rendahnya tingkat steroid ovarium secara bersamaan dapat menawarkan lingkungan endometrium yang lebih baik untuk implantasi yang dapat mengarah pada hasil yang lebih baik. ${ }^{13}$ Perbedaan penelitian ini dengan penelitian tersebut adalah jumlah sampel yang besar serta perbandingan dilakukan pada siklus fresh dan frozen embrio transfer. Sedangkan penelitian ini sampel lebih sedikit dan hanya pada siklus transfer embrio simpan beku.

Pada penelitian ini kualitas embrio derajat 1 dan derajat 1-2 lebih banyak didapatkan pada subyek non endometriosis $(56,64 \%)$ dibandingkan pada subyek dengan endometriosis (40,47\%). Data klinis menunjukkan kemungkinan efek negatif dari endometriosis berat pada implantasi. Efek ini dimediasi melalui penurunan kualitas embrio, mungkin akibat dari penurunan jumlah embrio yang tersedia. Penyebab lebih lanjut kemungkinan infertilitas terkait endometriosis adalah gangguan implantasiembrio. Telah dipostulatkan bahwa embrio yang berasal dari wanita dengan endometriosis tampaknya berkembang lebih lambat dibandingkan dengan embrio yang berasal dari wanita dengan penyakit tuba. ${ }^{14}$ Wanita dengan endometriosis sedang hingga berat yang menerima oosit dari wanita bebas penyakit dalam siklus donasi oosit tampaknya memiliki reseptif endometrium normal dan tingkat kehamilan sebaliknya ketika donor oosit dari wanita dengan endometriosis ditransfer ke wanita tanpa endometriosis, tingkat implantasi lebih rendah dan kualitas embrio berkurang. ${ }^{15}$ Namun demikian, kemungkinan dampak endometriosis pada reseptivitas endometrium tampaknya dapat dikoreksi dengan perawatan klasik endometriosis yaitu dengan hormonal, analog $\mathrm{GnRH}$, dan pembedahan. ${ }^{16}$ Pada penelitian ini koreksi terhadap reseptivitas endometrium melalui terapi hormonal terhadap endometriosis tidak dinilai sehingga kemungkinan pengaruhnya terhadap keberhasilan IVF tidak dapat dinilai.

Semua pasien yang menjalani IVF dalam penelitian ini telah dilakukan pembedahan terkait endometriosis hal ini kemungkinan berpengaruh terhadap keberhasilan pencapaian kehamilan. Namun dalam penelitian ini tidak terdapat data tentang $\mathrm{AMH}$ sebelum dan sesudah operasi maupun data $\mathrm{AMH}$ sebelum tindakan IVF. Adanya tindakan pembedahan pada pasien endometriosis terutama pada endometrioma telah terbukti menurunkan tingkat $\mathrm{AMH}$ sejak 1 bulan setelah laproskopi. ${ }^{17}$ Penurunan $\mathrm{AMH}$ ini berpengaruh terhadap cadangan oosit dalam ovarium. Kerusakan ovarium yang disebabkan oleh pembedahan adalah penyebab utamanya. Hal ini karena kurangnya area pembelahan yang jelas antara stroma endometrium seperti pada kista endometriosis dan jaringan ovarium dapat menyebabkan kerusakan jaringan ovarium sehat yang berdekatan, yang dapat membahayakan cadangan ovarium. Dalam 
beberapa penelitian menemukan bahwa kadar FSH serum basal meningkat secara signifikan pada wanita dengan endometriosis berat, sehingga mendukung pendapat hilangnya fungsi ovarium seiring dengan pemberatan penyakit. ${ }^{18}$ Barri et al., menemukan bahwa pasien dengan endometriosis memiliki tingkat $\mathrm{FSH}$ yang lebih tinggi dan AFC (antral follicle count) lebih rendah daripada pasien dengan infertilitas faktor pria sebelum perawatan apa pun, terutama pembedahan. ${ }^{19}$

Hasil ini sesuai dengan ulasan yang dilakukan oleh Barbosa et al, yang menyimpulkan bahwa hasil reproduksi pada wanita dengan endometriosis yang mencoba teknik reproduksi berbantu tidak boleh dianggap lebih buruk, dan bahwa probabilitas kelahiran hidup dan kehamilan klinis tidak relatif berbeda dari yang dialami wanita tanpa endometriosis. Dan sebagian besar pasien dengan endometriosis telah memiliki diagnosis bedah (dengan reseksi) dan mungkin tidak ada lesi aktif selama IVF, hal ini mungkin menjelaskan mengapa tidak ada perbedaan bermakna antara kelompok endometriosis dan non endometriosis. ${ }^{20}$

Wanita dengan endometriosis derajat I dan II yang menjalani IVF / ICSI memiliki waktu yang jauh lebih singkat untuk dapat hamil dan LBR yang lebih tinggi jika semua endometriosis yang terlihat sepenuhnya telah dihilangkan pada saat pembedahan diagnostik. Temuan ini menimbulkan pertanyaan, apakah semua wanita subfertil harus menjalani laparoskopi sebelum perawatan reproduksi yang dibantu, yang harus diselidiki dengan randomized controlled trial prospektif 21 . penelitian ini sependapat dengan Littman et al, 2005 bahwa pada pasien tertentu dengan beberapa siklus IVF yang gagal, peran terapi laparoskopi berpotensi besar, bahkan untuk endometriosis stadium I dan II. Meskipun hasil saat ini menyarankan untuk dilakukan terapi pada endometriosis minimal dan ringan, namun tidak cukup untuk dapat menyimpulkan apakah operasi laparoskopi primer dari semua pasien subfertil akan lebih unggul daripada inisiasi langsung IVF / ICSI tanpa operasi, hal ini harus dilanjutkan dalam randomized controlled trial. ${ }^{21}$

Dalam studi lain, tingkat implantasi pada pasien dengan endometriosis lebih rendah dibandingkan dengan pasien infertilitas tuba atau yang tidak dijelaskan, tanpa perbedaan yang diamati mengenai kualitas oosit dan tingkat fertilisasinya. ${ }^{22}$ Peningkatan apoptosis, perubahan dalam siklus sel dan kejadian stres oksidatif yang lebih tinggi tampak pada sel granulosa yang berasal dari wanita dengan semua tahap endometriosis, termasuk endometrioma, bila dibandingkan dengan sel granulosa wanita dengan penyebab infertilitas lainnya. Oleh karena itu kualitas oosit sangat terpengaruh pada endometriosis. ${ }^{23}$

Namun demikian, penelitian yang lebih baru dengan stimulasi long protocol $\mathrm{GnRH}$ agonis tidak menemukan hasil ini: Hickman mempelajari 149 siklus, membandingkan pasien dengan endometriosis dengan mereka yang mengalami infertilitas tuba; tingkat implantasi adalah sebanding antara kelompok (masing-masing $28,0 \%$ berbanding 29,8\%). ${ }^{24}$ Coccia et. al., melakukan penelitian yang kuat dengan risiko minimal bias, dan tidak menemukan perbedaan yang signifikan dalam keseluruhan tingkat implantasi. Tetapi dalam analisis sub kelompok, mereka menemukan pengurangan implantasi dengan tahap sedang dan berat (III dan IV). ${ }^{25}$ Namun, hasil ini tidak ditemukan dalam studi lain dari 895 siklus ICSI pada pasien endometriotik: tingkat implantasi diperkirakan $12,9 \%$ pada kontrol, $10,7 \%$ pada tahap I dan II, dan $11,2 \%$ pada tahap III dan IV. ${ }^{26}$

Subyek dalam penelitian ini mengalami miscarriage sebanyak 102 subyek (82,9\%) sedangkan yang tidak terjadi miscarriage sebanyak 21 orang $(17,1 \%)$. Penderita endometriosis yang mengalami miscarriage sebanyak 4 subyek $(11,4 \%)$. Dari analisis bivariat endometriosis tidak terhadap hubungan yang bermakna terhadap kejadian miscarriage dengan $p=0,294 \quad(p>0,05)$. Hasil ini sejalan dengan penelitian cross sectional di Italia yaitu wanita dengan endometriosis tampaknya tidak memiliki peningkatan risiko keguguran. Hasil penelitian tersebut tidak menunjukkan hubungan endometiosis dengan abortus spontan pada wanita yang mencapai kehamilan tunggal dengan IVF. ${ }^{27}$

Dari analisis bivariate dan multivariate antara variabel bebas dengan variabel luar terdapat hubungan antara usia, infertilitas, ketebalan endometrium, usia embrio dan kualitas embrio 
dengan kehamilan biokimiawi. Sedangkan kehamilan klinis berhubungan dengan usia, jumlah embrio, dan riwayat operasi sebelumnya. Untuk kejadian miscarriage berhubungan dengan protokol stimulasi.

Dalam penelitian ini usia kurang dari 35 tahun memiliki hubungan yang bermakna dengan keberhasilan mencapai kehamilan biokimiawi dengan $R R=0,001(R R<0,05)$ dengan nilai OR 2,01 $(\mathrm{Cl}$ $95 \%$ 1,38-3,06), sehingga usia kurang dari 35 tahun memiliki kemungkinan berhasil mencapai kehamilan klinis 2,01 kali lebih tinggi dibandingkan usia lebih dari 35 tahun. Hal ini sejalan dengan cohort prospektif di Iran yang menunjukkan hubungan yang signifikan antara tingkat AMH dan keberhasilan IVF pada wanita usia kurang dari $35 .^{28}$ Variabel usia juga berpengaruh terhadap kehamilan klinis $p=0,085$, OR $2,12 \mathrm{Cl} 95 \%$ 0,90-4,98), namun tidak mempengaruhi kejadian misscarriage.

Pada subyek dengan infertil sekunder mempunyai pengaruh signifikan dan mempunyai kemungkinan untuk hamil biokimiawi 1,90 kali lebih besar dibandingkan subyek dengan infertil primer $\mathrm{P}=0,004 \quad(\mathrm{P}<0,05) \quad \mathrm{OR}=1,90 \quad(\mathrm{Cl} 95 \% 1,22-2,98)$. Riwayat kehamilan sebelumnya meningkatkan angka kesuksesan IVF, terutama jika kehamilan sebelumnya juga merupakan hasil IVF dan berhasil melahirkan hidup. ${ }^{29}$

Ketebalan endometrium lebih dari sama dengan $8 \mathrm{~mm}$ mempunyai hubungan yang bermakna terhadap kehamilan biokimiawi $p=0,022(P<0,05)$, dan mempunyai kemungkinan hamil 1,83 kali lebih besar daripada ketebalan ndometrium kurang dari $8 \mathrm{~mm}$ (OR=1,83 Cl 95\% 1,09-3,07). Hal ini sejalan dengan beberapa penelitian yang mengevaluasi hubungan antara ketebalan endometrium dengan luaran setelah dilakukan fresh IVF, dan hasilnya angka kehamilan pada wanita dengan ketebalan endometrium lebih dari $9 \mathrm{~mm}$ lebih tinggi daripada wanita dengan ketebalan endometrium 7-8 $\mathrm{mm}$ yang dinilai pada saat embrio transfer. Ketebalan endometrium adalah faktor utama dalam mengidentifikasi waktu untuk suplemetasi progesteron dan waktu untuk frozen embryo transfer. ${ }^{30}$
Dari hasil penelitian ini usia embrio D5 kemungkinan dapat mencapai kehamilan biokimiawi lebih besar 2,21 kali daripada embrio usia D3 dan bermakna secara statistik (OR 2,21, p=0,00 Cl 95\% 1,39-3,24). Studi di Amerika mengemukakan jika IVF denga embrio D5 mempunyai kemungkinan hamil yang lebih besar dan kemungkinan kehamilan abnormal yang lebih rendah meskipun hal ini masih memerlukan studi yang lebih dalam lagi. ${ }^{31}$

Keberhasilan mencapai kehamilan biokimiawi juga lebih besar 2,78 kali lebih besar jika mentransfer 2 embrio dengan masing-masing kualitas 1 daripada mengimplantasikan dengan 1 atau 2 dengan kualitas embrio yang lain $(O R 2,19, p=0,072 \mathrm{Cl} 95 \% 0,93$ $5,16)$. Sedangkan kehamilan klinis berhubungan dengan jumlah embrio $p=0,035$ yang ditrasnfer namun untuk kualitas tidak bermakna secara statistik.

Variabel protokol stimulasi ovarium dengan GnRH agonis/long protocol berhubungan dengan kejadian miscarriage namun tidak meningkatkan kejadiannya ( $p=0,011$ OR 0,213 Cl 95\% 0,06-0,70). Hasil yang sama diperoleh dari studi di Iran yang menunjukkan tingkat implantasi lebih baik pada wanita yang distimulasi dengan protokol panjang $\mathrm{GnRH}$ agonis daripada yang distimulasi dengan protokol GnRH antagonis. Umumnya setelah distimulasi dengan protokol panjang jumlah oosit yang diperoleh pada wanita dengan ovarium normal lebih banyak sehingga jumlah embrio yang akan ditransfer maupun disimpan beku lebih banyak, sehingga tingkat pembatalan embrio transfer lebih kecil dan jumlah kehamilan meningkat dibandingkan dengan stimulasi menggunakan protokol lainnya. Sedangkan peneliti lain melaporkan tidak ada perbedaan signifikan antara protokol GnRH agonis dan protokol GnRH antagonis pada siklus transfer embrio simpan beku. ${ }^{32}$

\section{KESIMPULAN DAN SARAN}

Angka kehamilan biokimiawi dan kehamilan klinis pada penderita endometriosis yang telah menjalani operasi sedikit lebih tinggi dibandingkan dengan non endometriosis meskipun secara statistik tidak berpengaruh terhadap keberhasilan mencapai 
kehamilan baik biokimiawi maupun kehamilan klinis. Angka kejadian miscarriage pada penderita endometriosis lebih tinggi daripada penderita non endometriosis namun tidak bermakna secara statistik.

Kehamilan biokimiawi dipengaruhi secara signifikan oleh usia ibu, status infertilitas, ketebalan endometrium, usia embrio dan kualitas embrio. Sedangkan kehamilan klinis berhubungan dengan usia, ketebalan endometrium, usia embrio dan kualitas embrio. Untuk kejadian miscarriage dipengaruhi oleh protokol stimulasi ovarium.

\section{DAFTAR PUSTAKA}

1. Benaglia L, Candotti G, Papaleo E, Pagliardini L, Leonari $M$, Reschini $M$,Quaranta L,Munaretto $M$, Viganò $\mathrm{P}$, Candiani $\mathrm{M}$, Vercellini $\mathrm{P}$, and Somigliana E. 2016. Pregnancy Outcome in Women with Endometriosis Achieving Pregnancy with IVF. Hum. Reprod, 31(12): 2730-2736

2. Tanbo Tom and Fedorscsak P. 2017. Endometriosisassosciated infertility: aspect of pathophysiological mechanisms and treatment options. Acta Obstetricia et Gynecologica Scandinavica, 96(6): 659-667

3. Jacobson, T., Duffy, J., Barlow, D., Farquhar, C., Koninckx, P. and Olive, D., 2014. Laparoscopic surgery for subfertility associated with endometriosis. Cochrane Database of Systematic Reviews,

4. Alkudmani B, Buell D, Salman J, Librach C, Sharma P. A. 2014. In Vitro Fertilization (IVF) Success Rates in Patients with Surgically Diagnosed Endometriosis and Effect of Time Interval from Surgery to IVF Cycle. fertstert.org/article. diunduh dari https://doi. org/10.1016/j.ferntert.2014.07.1057

5. Opøien, H., Fedorcsak, P., Åbyholm, T. and Tanbo, T., 2011. Complete surgical removal of minimal and mild endometriosis improves outcome of subsequent IVF/ICSI treatment. Reproductive BioMedicine Online, 23(3): 389-395

6. Borges Jr., E., Braga, D., Setti, A., Vingris, L., Figueira, R. and laconelli Jr, A., 2015. Endometriosis Affects Oocyte Morphology in Intracytoplasmic Sperm Injection Cycles. JBRA Assisted Reproduction, 19(4)

7. Surrey ES. 2014. Endometriosis-Related Infertility: The Role of the Assisted Reproductive Technologies. Hindawi Publishing Corporation. BioMed Research International Volume 2015, Article ID 482959, 8 pages

8. Lin XN, Wei ML, Tong XM, Xu WH, Zhou F, Huang QX, Wen GF, Zhang SY. 2012. Outcome of In Vitro Fertilization in endometriosis-associated infertility: a 5-year database cohort study. Chin Med J (Engl) Aug, 125(15): 2688-93. PMID: 22931976

9. Evans J, Hannan NJ, Edgell TA, et al. 2014. Fresh versus frozen embryo transfer: backing clinical decisions with scientific and clinical evidence. Hum Reprod 2014; 20: 808-21

10. Salumets Andres, Suikari Anne Maria, Makinem Sirpa, Karro Helle, Roos Anu and Tuuri Timmo. 2006. Frozen Embryo Transfer: Implication of Clinical and Embriological Factors on the Pregnancy Outcome. Hum. Rep., (21): 2368-2374

11. Shin, J., Jeong, Y., Nho, E. and Jee, B., 2018. Clinical outcomes of frozen embryo transfer cycles after freeze-all policy to prevent ovarian hyperstimulation syndrome. Obstetrics \& Gynecology Science, 61(4): 497

12. Queiroz Vaz G, Evangelista AV, Almeida Cardoso MC, Gallo P, Erthal MC, Pinho Oliveira MA. 2017 Frozen embryo transfer cycles in women with deep endometriosis. Gynecol Endocrinol, Jul; 33(7): 540-543

13. Ahmed M.F.Mohammed, Spyridon Chouliaras, Carolyn J.P. Jones, Luciano G, Nardo. 2011. Live Birth Rate in Frozen Embryo Transfer Cycles in Women with Endometriosis. European Journal of Obsterics and Ginecology and Reproductive Biology; 10.1016/j.ejorgb.2011.01.020

14. Sanchez, A., Vanni, V., Bartiromo, L., Papaleo, E., Zilberberg, E., Candiani, M., Orvieto, R. and Viganò, P., 2017. Is the oocyte quality affected by endometriosis? A review of the literature. Journal of Ovarian Research, 10(1)

15. Hauzman, E., Pellicer, A. and Garcia-Velasco, J., 2013. Oocyte Donation and Endometriosis: What Are the Lessons?. Seminars in Reproductive Medicine, 31(02): 173-177

16. Cazalis CG, Koskas Martin, Scali Sandrine Cohen, Luton Dominique, Yazbeck Chadi. 2012. Endometriosis and implantation: Myths and facts. Middle East Fertility Society Journal, 17: 79-81

17. Mostaejeran Fatemeh, Hamoush Zeinab, and Rouholamin Safoura. 2015. Evaluation of antimullerian hormone levels before and after laparoscopic management of endometriosis. Adv Biomed Res, 4: 182

18. Hock DL, Sharafi K, Dagostino L, Kemmann E, Seifer DB. 2001. J Reprod Med. Jan; 46(1): 7-10

19. Barri PN, Coroleu B, Tur R, Barri-Soldevila PN, Rodríguezl.2010. Endometriosis-associatedinfertility surgery and IVF a comprehensive therapeutic approach. Reprod Biomed Online.21:179-185. doi: 10.1016/j.rbmo.2010.04.026

20. Barbosa MA, Teixeira DM, Navarro PA, et al. 2014. Impact of endometriosis and its staging on assisted reproduction outcome: systematic review and metaanalysis. Ultrasound Obstet Gynecol, 44: 261-78 
21. Opoien HK, Fedorcsak P, Omland AK, Abyholm T, Bjercke S, Ertzeid G, Oldereid N, Mellembakken JR, Tanbo T. 2012. In Vitro Fertilization is a successful treatment in endometriosis-associated infertility. Fertil Steril. Apr 2012; 97(4): 912-8

22. Singh, N., Tiwari, A., Vanamail, P., Lata, K., Malhotra, N. and Naha, M., 2014. Effect of endometriosis on implantation rates when compared to tubal factor in fresh non donor In Vitro Fertilization cycles. Journal of Human Reproductive Sciences, 7(2): 143

23. Goud, P., Goud, A., Joshi, N., Puscheck, E., Diamond, M. and Abu-Soud, H., 2014. Dynamics of nitric oxide, altered follicular microenvironment, and oocyte quality in women with endometriosis. Fertility and Sterility, 102(1): 151-159.e5.

24. Hickman TN. 2002. Impact of endometriosis on implantation. Data from the Wilford Hall Medical Center IVF-ET Program. J Reprod Med; 47(10): 801-8

25. Coccia ME, Rizello F, Mariani G, Bulletti C, Palagiano A, Scarselli G. 2011. Impact of endometriosis on In Vitro Fertilization and embryo transfer cycles in young women: a stage-dependent interference. Acta Obstet Gynecol Scand; 90(11): 1232-8

26. Bukulmez O, Yarali H, Gurgan T. 2001. The presence and extent of endometriosis do not effect clinical pregnancy and implantation rates in patients undergoing intracytoplasmic sperm injection. Eur J Obstet Gynecol Reprod Biol 2001; 96(1): 102-7

27. Leonardi M, M.D., Papaleo E, M.D., Reschini M, M.Sc., Pagliardini L, M.D., Benaglia L, M.D. et al. 2016. Risk of miscarriage in women with endometriosis: insights from In Vitro Fertilization cycles. Fertil Steril, 106(2): 386-392.e3.
28. Azra Azmoudeh, Zahra Shahraki ID, Fatemeh-Sadat Hoseini, Firoozeh Akbari-Asbagh1, Fatemeh Davari Tanha, Forough Mortazavi. 2018. In Vitro Fertilization Success and Associated Factors: A Prospective Cohort Study. International Journal of Women's Health and Reproduction Sciences, 6(3): 350-355

29. Eftekhar, M., Rahmani, E., \& Pourmasumi, S. 2014. Evaluation of clinical factors influencing pregnancy rate in frozen embryo transfer. Iranian journal of reproductive medicine, 12(7): 513-518

30. Shaodi, Z., Qiuyuan, L., Yisha, Y. and Cuilian, Z., 2020. The effect of endometrial thickness on pregnancy outcomes of frozen-thawed embryo transfer cycles which underwent hormone replacement therapy. PLOS ONE, 15(9): p.e0239120.

31. Kathiresan A, E. T. Wang, N. Greene, C. J. Alexander, M. D. Pisarska. 2015. Abnormal implantation in day 3 versus day 5 embryo transfers in fresh ivf cycles: an analysis from the society for assisted reproductive technology database. Fertil Steril Volume. 104(3) Supplement: 99

32. Ashrafi, M., Jahangiri, N., Hassani, F., Akhoond, M. and Madani, T. The factors affecting the outcome of frozen-thawed embryo transfer cycle. Taiwanese Journal of Obstetrics and Gynecology. 2011; 50(2): 159-164 